\title{
A prospective study of patients with large congenital melanocytic nevi and the risk of melanoma*
}

\author{
Ana Carolina Leite Viana ${ }^{1}$ \\ Bernardo Gontijo ${ }^{1}$
}

\author{
Eugênio Marcos Andrade Goulart ${ }^{2}$ \\ Flávia Vasques Bittencourt ${ }^{1}$
}

DOI: http://dx.doi.org/10.1590/abd1806-4841.20175176

\begin{abstract}
BACKGROUND: Large congenital melanocytic nevus (LCMN) is considered a risk factor for melanoma, although the magnitude of this risk is controversial.

Oвјестіve: To evaluate the risk of melanoma development in patients with LCMN seen at a dermatology referral center in Brazil during a twelve-year period. To the best of our knowledge, there are no published similar studies on large congenital melanocytic nevus in South America.

METHODS: Our prospective cohort included only patients with congenital nevi $\geq 20 \mathrm{~cm}$. The cumulative risk of developing melanoma and the standardized morbidity ratio were calculated for patients followed up prospectively for at least 1 month. RESUlts: Sixty-three patients were enrolled in this study. One patient who developed melanoma prior to enrollment was excluded, and five were eliminated because of insufficient follow-up time. Mean follow-up for the remaining 57 patients was 5.5 years (median 5.2 years). Median age of entry into the study was 2.6 years. Most patients (75.4\%) underwent only clinical observation. Melanomas occurred in 2 (3.5\%) patients. Five-year cumulative risk for melanoma was 4.8\% (95\% CI: 1.9-11.5\%). Standardized morbidity ratio was 1584 (95\% CI: 266-5232, p<0.001).

STUDY LimitATIONS: The small sample size reduces the accuracy of risk estimates.

ConClusions: This study analyzed prospectively for the first time data from South America demonstrating that patients with LCMN have a higher risk of developing melanoma than the general population $(p<0.001)$.

Keywords: Melanoma; Nevus, pigmented; Nevi and melanomas; Risk
\end{abstract}

\section{INTRODUCTION}

Large congenital melanocytic nevus (LCMN) most commonly appears between the fifth and $24^{\text {th }}$ weeks of gestation and has an estimated incidence of less than one in 20,000 newborns. ${ }^{1,2}$ A morphological error in the neuroectoderm during embryogenesis is believed to lead to the unregulated growth of melanoblasts, the

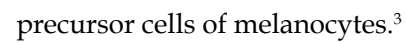

Several criteria have been used by different authors to define a congenital melanocytic nevus $(\mathrm{CMN})$ as large. ${ }^{4-9}$ The system proposed by Kopf et al. ${ }^{10}$, the most accepted, arbitrarily classifies $\mathrm{CMN}$, according to the size the lesion will reach in adulthood, in small $(<1.5 \mathrm{~cm})$, medium $(1.5-19.9 \mathrm{~cm})$, and large or giant (at least $20 \mathrm{~cm}){ }^{7,11-19}$

Although rare, LCMN is important because it may be associated with serious complications, such as melanoma and central nervous system impairment (neurocutaneous melanosis). LCMNs also have a major psychosocial impact on patients and their families, often due to their unsightly appearance. ${ }^{11,12,20-22}$ Hence, a therapeutic approach is often quite distressing for patients. However, the decision regarding the best approach can also cause high anxiety among health professionals, since there is no true consensus on this issue. ${ }^{14,23}$ Thus, a more accurate estimate of these risks would be highly desirable to assist in making the decision about whether or not an LCMN should be prophylactically excised.

In this sense, the present study was conceived to evaluate the risk of melanomas in patients with LCMNs who were examined at a referral dermatology center in Brazil. To the best of our knowledge, there are few prospective studies assessing the risk of melanoma in LCMN. ${ }^{17,24}$ To contribute to the expansion of the knowledge in this area, the Registry of Large Congenital Melanocytic Nevi was created at the Federal University of Minas Gerais (UFMG), Belo Horizonte, Brazil, in 1999.

\section{METHODS}

This prospective study started in 1999 and included all patients with LCMNs evaluated in the Department of Dermatology at UFMG from 1999 to 2011. The study was approved by the Ethics Review Board of the Institution.

An LCMN was defined as a melanocytic nevus present at birth that has a diameter of $\geq 20 \mathrm{~cm}$ (or that is expected to reach 20 $\mathrm{cm}$ at any time in life, according to the available criteria for estimating the diameter of a nevus in adulthood). ${ }^{25,26}$

\section{Received on 25.09.2015}

Approved by the Advisory Board and accepted for publication on 02.04.2016

* Study conducted at the Dermatology Unity - Hospital das Clinicas - Federal University of Minas Gerais- Belo Horizonte (MG), Brazil.

Financial support: None.

Conflict of interest: None.

Dermatology Unity - Hospital das Clinicas - Universidade Federal de Minas Gerais (UFMG) - Belo Horizonte (MG), Brazil.

Department of Pediatrics - School of Medicine, Universidade Federal de Minas Gerais (UFMG) - Belo Horizonte (MG), Brazil. 
Data from each patient included age at the first appointment, gender, skin color, characteristics of the nevus (size, location), number of satellite lesions, follow-up period, personal and family history of melanoma, neurological symptoms, clinical neurological imaging, presence of neurocutaneous melanosis, type of treatment, and family history of congenital nevi.

The follow-up period was defined as the interval between the date of the first and last visit or contact (or the date of melanoma diagnosis, when applicable). Follow up was performed during the patient's periodic appointments at the Clinic. In few cases, information was updated through phone contacts.

Patients whose follow-up was less than 1 month and/or those who had a diagnosis of melanoma before entering the study were excluded from statistical analysis.

Survival was calculated by the Kaplan-Meier analysis. ${ }^{27}$ Thus, it was possible to determine the cumulative risk of the occurrence of a melanoma in this population over a five-year period, as well as its 95\% Confidence Interval (CI).

The latest data from the Cancer Registry of the city of Belo Horizonte, Brazil, available at the Brazilian National Institute of Cancer, were used for the calculation of the standardized morbidity ratio. ${ }^{28}$ The Cancer Registry actively searches and analyzes data on cancer incidence, according to global technical standards and following quality criteria that measure the coverage and validity of data. Information on the incidence of melanomas in the study group was matched for age, gender, and follow-up time to determine the number of tumors expected to be found in the sample under examination when subjected to the same incidence rates of melanoma as the general population. The ratio between the number of melanomas observed and the expected number (standardized morbidity ratio), which is interpreted as a measure of relative risk, ${ }^{8,2,20,26}$ was then calculated. The $95 \% \mathrm{CI}$ was obtained by the mid-p exact test.

\section{RESULTS}

Six of the 63 patients recruited were excluded: five for insufficient follow-up time ( $<1$ month) and one who had developed a melanoma prior to enrollment. Median age at baseline was 2.6 years (mean 8.3 years, SD 12.1 years) (Table 1$)$. Twenty patients $(35.1 \%$ ) were under one year of age upon entering the Cancer Registry, and $35(61.4 \%)$ were admitted before the age of 5 (Figure 1). The mean follow-up time was 5.5 years (SD 3.8 years, median 5.2 years).

Twenty-nine patients (50.9\%) were males (ratio 1.04:1); $56.1 \%$ were Caucasians, $38.6 \%$ mulattos, and $5.3 \%$ blacks. The predominant location of the LCMN was the trunk (68.4\%). In $17.5 \%$ of patients the lesion was located on the head and/or neck, whereas in $14.1 \%$ it was restricted to the limbs. The "bathing trunk" variety was seen in $33.3 \%$ of the patients, and in $55.5 \%$ the lesion was over $40 \mathrm{~cm}$ (Figure 2). Satellite melanocytic nevi were present in $84.2 \%$ of the patients.

No patient informed a family history of melanoma. Family history of CMN was obtained in $35.1 \%$ of the cases.

Four patients $(7.0 \%)$ showed symptoms of neurological impairment (seizures and/or delay in neuropsychomotor development), but only one patient was diagnosed with neurocutaneous melanosis, which proved to be asymptomatic. Magnetic resonance

\begin{tabular}{|c|c|c|}
\hline Parameter & $\mathbf{n}$ & $\%$ \\
\hline \multicolumn{3}{|l|}{ Gender } \\
\hline Male & 29 & 50.9 \\
\hline Female & 28 & 49.1 \\
\hline \multicolumn{3}{|l|}{ Age at start of follow-up (years) } \\
\hline Mean \pm standard deviation & \multicolumn{2}{|c|}{$8.3 \pm 12.1$} \\
\hline Median & \multicolumn{2}{|c|}{2.6} \\
\hline \multicolumn{3}{|l|}{ Follow-up (years) } \\
\hline Mean \pm standard deviation & \multicolumn{2}{|c|}{$5.5 \pm 3.8$} \\
\hline Median & \multicolumn{2}{|c|}{5.2} \\
\hline \multicolumn{3}{|l|}{ Skin color } \\
\hline Caucasian & 32 & 56.1 \\
\hline Mulatto & 22 & 38.6 \\
\hline Black & 3 & 5.3 \\
\hline \multicolumn{3}{|l|}{ Family history of melanoma } \\
\hline Yes & 0 & 0 \\
\hline No & 55 & 96.5 \\
\hline No information & 2 & 3.5 \\
\hline \multicolumn{3}{|l|}{ Family history of CMN } \\
\hline Yes & 20 & 35.1 \\
\hline No & 32 & 56.1 \\
\hline No information & 5 & 8.8 \\
\hline \multicolumn{3}{|l|}{ Localization of LCMN } \\
\hline Back & 16 & 28.1 \\
\hline Front trunk & 4 & 7.0 \\
\hline Bathing trunk variety & 19 & 33.3 \\
\hline Upper limb & 1 & 1.8 \\
\hline Lower $\operatorname{limb}$ & 7 & 12.3 \\
\hline Head/neck & 10 & 17.5 \\
\hline \multicolumn{3}{|l|}{ Number of satellite nevi } \\
\hline Zero & 8 & 14.0 \\
\hline $1-9$ & 10 & 17.5 \\
\hline $10-29$ & 9 & 15.8 \\
\hline $30-49$ & 8 & 14.0 \\
\hline$\geq 50$ & 21 & 36.9 \\
\hline No information & 1 & 1.8 \\
\hline \multicolumn{3}{|l|}{ Neurological symptoms } \\
\hline Yes & 4 & 7.0 \\
\hline No & 53 & 93.0 \\
\hline \multicolumn{3}{|l|}{ Neurological work-up ${ }^{\dagger}$} \\
\hline None & 20 & 35.1 \\
\hline Computed tomography & 28 & 49.1 \\
\hline Magnetic resonance imaging & 11 & 19.3 \\
\hline No information & 4 & 7.0 \\
\hline \multicolumn{3}{|l|}{ Neurocutaneous melanosis } \\
\hline Symptomatic & 0 & 0 \\
\hline Asymptomatic & 1 & 1.8 \\
\hline Absent or unknown & 56 & 98.2 \\
\hline \multicolumn{3}{|l|}{ Treatment of LCMN ${ }^{\ddagger}$} \\
\hline Clinical observation & 43 & 75.4 \\
\hline Partial excision & 6 & 10.5 \\
\hline Complete excision & 3 & 5.3 \\
\hline Other & 9 & 15.8 \\
\hline Dermabrasion & 4 & 7.0 \\
\hline Laser & 2 & 3.5 \\
\hline \multicolumn{3}{|l|}{ Excision of satellite lesions } \\
\hline Yes & 5 & 8.8 \\
\hline No & 50 & 87.7 \\
\hline No information & 2 & 3.5 \\
\hline Occurrence of melanoma & & \\
\hline Yes & 2 & 3.5 \\
\hline No & 55 & 96.5 \\
\hline
\end{tabular}

CMN - congenital melanocytic nevus; LCMN - large congenital melanocytic nevus † Twelve patients underwent more than one examination. $\ddagger$ Three patients had undergone more than one type of invasive treatment. 
imaging (MRI) was performed on $19.3 \%$ of the subjects, while computed tomography (CT) on $49.1 \%$.

Most patients (75.4\%) underwent only clinical observation. In totum excision was performed in three $(5.3 \%)$ patients. Other therapeutic modalities included dermabrasion $(7.0 \%)$ and laser therapy $(3.5 \%)$. Five $(8.8 \%)$ patients had one or more satellite melanocytic lesions removed for cosmetic reasons.

Melanoma developed in two $(3.5 \%)$ of the 57 patients. The first patient was a female Caucasian infant with a bathing trunk LCMN and over 50 satellite lesions. The primary site of the tumor could not be determined, although a retroperitoneal origin was suggested. The second patient was a mulatto female child with a bathing trunk LCMN and numerous satellite lesions. At 4 years of

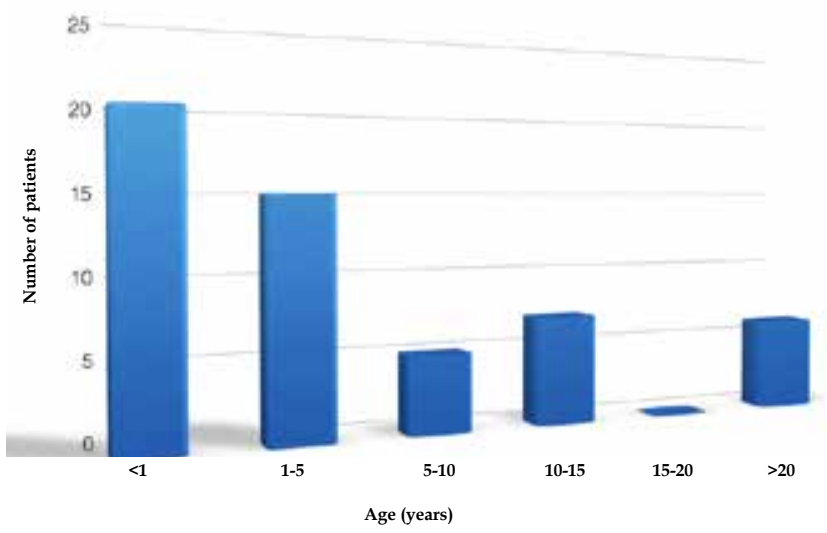

Figure 1: Age distribution of patients at the time of admission in the Registry of Large Congenital Melanocytic Nevi at UFMG
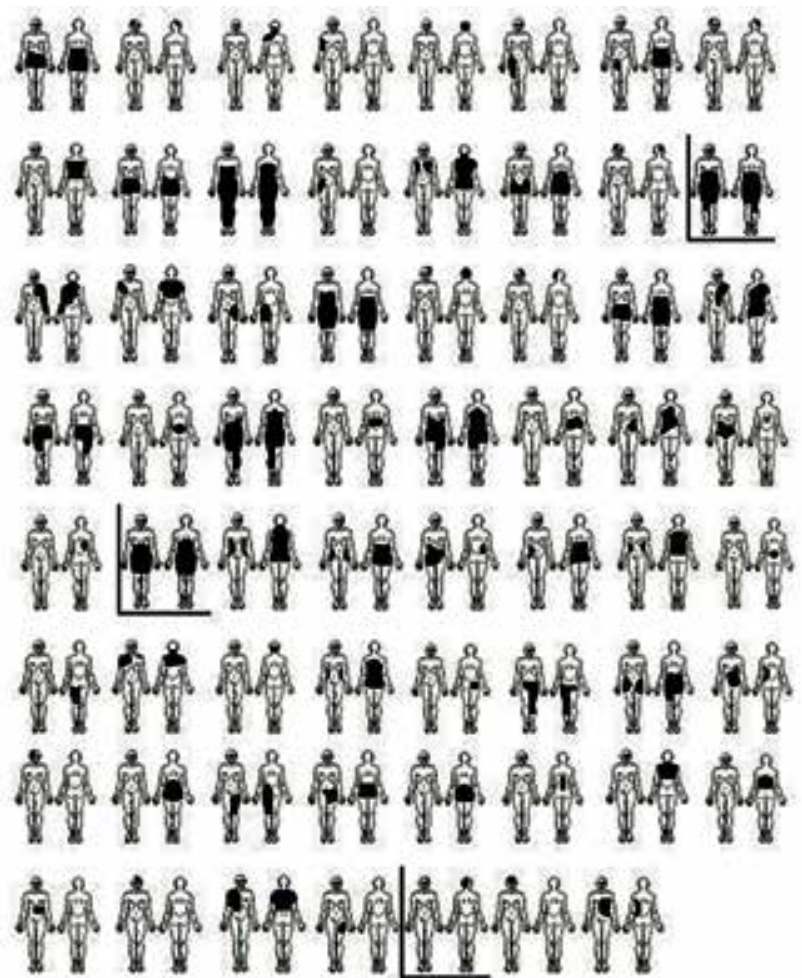

FIGURE 2: Large congenital melanocytic nevi location( the three marked images represent the melanoma cases) age, she developed a vaginal melanoma. For both children the diagnosis was performed by experienced pathologists and confirmed by immunohistochemistry, which was positive for HMB-45 and S- 100 . Both went into metastasis and died a few months after the diagnosis of the melanoma.

The five-year cumulative risk for developing melanoma (Figure 3) was 4.8\% (95\% CI: 1.9-11.5\%).

The expected number of melanomas in the studied population, matched by age, gender, and follow-up with the population of Belo Horizonte was 0.001263 . Thus, the standardized morbidity ratio was calculated as 1584 (95\% CI: 266-5232, p <0.001).

The third case of melanoma was excluded from the risk analysis of this study, since the diagnosis of the tumor was established before having been enrolled in the Cancer Registry. This patient was a 70-year-old white male with an LCMN in the scalp, with a superimposed melanoma.

\section{DISCUSSION}

Currently, there is considerable evidence available suggesting that individuals with LCMNs have an increased risk of developing melanomas. Although the range of variation in rates measuring the occurrence of melanoma across different studies has decreased in recent years, the incidence of malignancy in patients with LCMN is still controversial. ${ }^{29-31}$ The low prevalence of large nevi and the scarcity of comparable prospective studies contribute to the discrepancy between the estimated risks, often based on retrospective assessments. Thus, prospective studies with long follow-up periods are warranted to establish the true incidence of malignancy on LCMN. ${ }^{7}$

The present study's prospective cohort had a mean follow-up of 5.5 years (median 5.2 years), which was similar to other prospective studies that evaluated the risk of melanoma only in patients with LCMN. ${ }^{17,19,24,26}$ The median follow-up of individuals who did not develop malignancy was 5.7 years, a relatively long period of time. One important feature is that all patients have been examined and followed-up by the same observer (FVB).

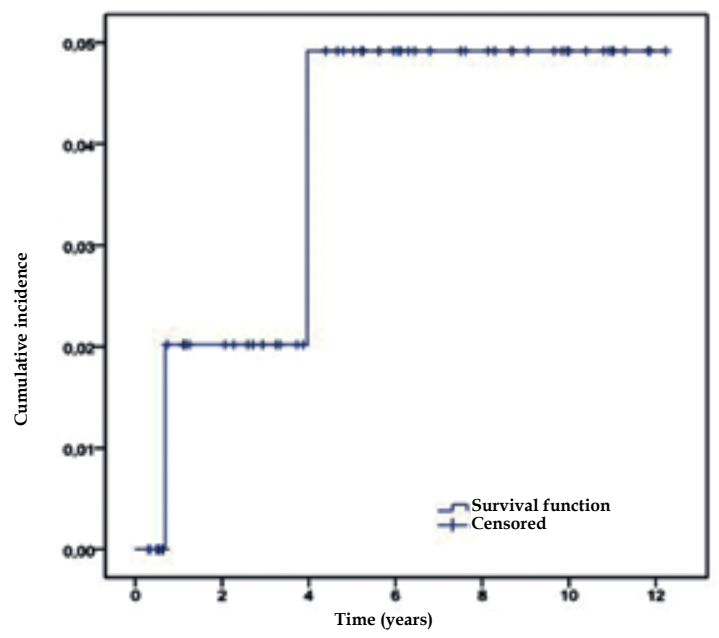

FIGURE 3 : Five-year cumulative risk of developing melanoma in the population of patients with large congenital melanocytic nevus evaluated at the Department of Dermatology at UFMG 
The median age of 2.6 years at the beginning of the follow-up and the high percentage of patients who entered the study before the age of $10(70.2 \%)$ indicate that enrollment occurred very early. This feature provides quality to the database since the late inclusion of subjects in a study leads to a survival bias. This is especially important when considering that the occurrence of malignancy is greater in the first 5 years of life. ${ }^{7,30,32,33}$ The median presents a more appropriate index than the mean in evaluating the age of the study population, taking into account the age range for the inclusion of patients (from the first hours of life to the age of 51 years). Despite the generally early admission in the study group, the entry of 22 patients after five years of age may have caused an underestimation of the risk of malignant transformation.

The five-year cumulative risk for developing melanoma in patients $(4.8 \%, 95 \% \mathrm{CI}: 1.9-11.5 \%)$ was similar to those found in other studies that used survival analysis. . $^{1924,26}$

The standardized morbidity ratio was 1584 (95\% CI: 266-5232, $\mathrm{p}<0.001)$. Published values vary between 51.6 and 2599.78,16,17,19,24,26,34 The large magnitude of the $95 \% \mathrm{CI}$, also observed in other studies that performed this calculation, ${ }^{7,8,19,24}$ illustrates that estimating the relative risk produces a low accuracy. This occurs because of the small sample size and the limited number of events (diagnosis of melanoma) observed.

One may suspect that the high value of the standardized morbidity ratio obtained in this study was influenced by factors such as the large number of very large nevi, the high percentage of patients who did not undergo interventional treatment, and the small sample size.

Krengel et al. ${ }^{16}$ showed in their systematic review that studies with smaller samples report a higher incidence of malignant transformation ( $p<0.0001$, chi-square for linear trend). Although the sample examined in this study is significant, mainly because all patients were evaluated in a single service, it may not have been large enough to avoid this bias.

Moreover, the fact that our service is a referral center for pigmented lesions may have caused an overestimation of risk assessment due to the possible referral of patients with more severe conditions (e.g., larger $\mathrm{CMN}$ ). As previously noted, one third $(33.3 \%)$ of our patients presented with the bathing trunk variety, and in $55.5 \%$ the lesion was over $40 \mathrm{~cm}$. These are important features, considering the fact that the larger the lesion, the greater the risk of malignant transformation. ${ }^{13,17}$

The study population has a high percentage $(75.4 \%)$ of patients who did not undergo interventional treatments when compared to other studies. ${ }^{7,8,17,35}$ The high rate of untreated patients in this study provides a unique opportunity to better understand the natural history of LCMN and favors a more realistic estimate of the risk of malignant transformation. ${ }^{10,34,36}$ This risk tends to be higher than those found in studies with a greater proportion of treated individuals, although there are no controlled studies demonstrating a reduction in the incidence of melanoma due to therapeutic interventions. ${ }^{29,35,37}$

Regarding other characteristics of the studied population, our study did not confirm the slight female predominance of LCMN demonstrated in some publications, generally ranging from about
1.17:1 to $1.46: 1 .^{7,13,16,17,30,33,38}$ In the cohort of Swerdlow et al. ${ }^{8}$, however, $\mathrm{CMN} \geq 20 \mathrm{~cm}$ were more predominant in male subjects (ratio 1.17:1). As for skin color distribution, the pattern observed in this study's sample was strictly similar to the general Brazilian population.

The most common location of LCMN was the trunk (68.4\%), as reported in other studies. ${ }^{17,19,24,39-41}$ In $85.9 \%$ of the study cases, LCMN had an axial location (defined as the involvement of the trunk, head, and/or neck).

The presence of satellite melanocytic nevi was observed in $84.2 \%$ of patients, and $66.7 \%$ presented ten or more lesions, figures similar to those reported in prior literature. ${ }^{17,40}$ Information on the occurrence of satellite nevi is important given that published studies show an association between the presence of these lesions and an increased risk of melanoma ${ }^{1,16,17}$ or neurocutaneous melanosis. ${ }^{17,25,42,43}$

Only $35.1 \%$ of the patients had a family history of CMN (any size), corroborating the reports that most cases of LCMN are sporadic. ${ }^{1,11,44}$

Regarding the two melanomas identified in the study population, one was found in the vaginal mucosa, while the primary site could not be identified in the second case. Studies report that about $50 \%$ of melanoma cases in individuals with LCMN are cutaneous and occur on the nevus. The main extracutaneous site is the central nervous system. In up to $24 \%$ of the cases, the origin of melanoma is unknown. ${ }^{17,19,40,45,46}$ Vaginal melanoma is a very rare occurrence, comprising $0.3-1.3 \%$ of all melanomas in women, with an annual incidence of 0.26 in 100,000 women in the United States. ${ }^{47}$ Melanoma of the lower genital tract is estimated to be responsible for only $3-7 \%$ of all cases of malignancies in that region. ${ }^{48}$

The patients who developed malignancy presented a LCMN in an axial location and more than 50 satellite lesions, which was similar to the trend observed in other studies. ${ }^{1,16,17,40}$

In the two cases, melanoma was diagnosed in the first five years of life, a time when the risk of malignancy is intensifed. $5,26,40,49,50$ The children who developed melanomas died within a few months after the diagnosis. It is well estblished that the prognosis of melanoma associated with LCMN is usually guarded. The mortality rate in cases with garment nevus is even higher, as observed in two of our deceased patients. ${ }^{16}$

The risk of melanoma associated with LCMN has proven to be smaller than was believed last century. Although there is no doubt that these patients are more prone to develop malignancies than the general population, and the magnitude of this effect is controversial, it is estimated that the risk of lifelong melanoma for these individuals is around 5\%. ${ }^{17,21,30}$ Therefore, the life-long probability of a patient with LCMN develop a melanoma seems small. However, the relative risk of cancer in these patients remains high. ${ }^{21,36,42}$

The decision to refer a patient for surgical treatment involves not only the technical difficulties of the procedure, but also the uncertainties about its efficacy in preventing melanomas. The recommendation of prophylactic surgical excision would be justified on the basis of the assumption that the melanoma may develop on the nevus lesion. However, up to $50 \%$ of melanomas found in patients with LCMN do not occur on the nevus itself. ${ }^{17,40}$ Moreover, the size of a deep LCMN may render complete resection impossible.

It is difficult to measure the impact of the total excision of 
the LCMN or other therapeutic measures on the risk of melanoma development. The reduction of melanocytic cells most likely decreases the incidence of malignancy. However, the heterogeneity of the studies regarding the type of treatment used and its extension hampers a quantitative analysis. Thus, there is currently no scientific evidence that surgical intervention changes the risk of melanoma or other complications from LCMN. ${ }^{16,37}$ Kinsler and Bulstrode ${ }^{29}$ draw attention to the fact that the cases in which CMN is likely to be completely removed are also those in which the risk of malignancy is lower because of their smaller size ${ }^{35}$ For these reasons, the interventionist approach of LCMN remains controversial. ${ }^{11,14,23}$ Removal of lesions that are more heterogeneous, thick, rough or, for some other reason, clinically difficult to be followed-up, should be considered. ${ }^{36,44}$
It is important to emphasize that even patients whose nevus was totally removed should be submitted to lifelong regular examinations of the entire skin and general medical examinations to facilitate detection of any malignancy in its early stages. ${ }^{11,20,26,29}$

\section{CONCLUSIONS}

There are few reports in the literature that analyze prospectively the risk of malignization of LCMN. Although it is common sense that such risk is greater in LCMN than in other nevi and in general population, its magnitude can not be precisely assessed, either due to the scarcity of studies or to methodological discrepancies. This study is the first in South America to prospectively evaluate these data and demonstrates that patients with LCMN have a greater risk of developing melanoma than the general population $(\mathrm{p}<0.001)$. $\square$

\section{REFERENCES}

1. Marghoob AA. Congenital melanocytic nevi: evaluation and management. Dermatol Clin. 2002;20:607-16, viii.

2. Castilla EE, da Graça Dutra M, Orioli-Parreiras IM. Epidemiology of congenital pigmented naevi: I. Incidence rates and relative frequencies. $\mathrm{Br} \mathrm{J}$ Dermatol. 1981;104:307-15

3. Takayama H, Nagashima $\mathrm{Y}$, Hara M, Takagi H, Mori M, Merlino G, et al. Immunohistochemical detection of the c-met proto-oncogene product in the congenital melanocytic nevus of an infant with neurocutaneous melanosis. J Am Acad Dermatol. 2001;44:538-40.

4. Greeley PW, Middleton AG, Curtin JW. Incidence of malignancy in giant pigmented nevi. Plast Reconstr Surg. 1965;36:26-37.

5. Kaplan EN. The risk of malignancy in large congenital nevi. Plast Reconstr Surg. 1974;53:421-8.

6. Lanier VC Jr, Pickrell KL, Georgiade NG. Congenital giant nevi: clinical and pathological considerations. Plast Reconstr Surg. 1976;58:48-54.

7. Watt AJ, Kotsis SV, Chung KC. Risk of melanoma arising in large congenital melanocytic nevi: a systematic review. Plast Reconstr Surg. 2004;113:1968-74.

8. Swerdlow AJ, English JS, Qiao Z. The risk of melanoma in patients with congenital nevi: a cohort study. J Am Acad Dermatol. 1995;32:595-9.

9. Kadonaga JN, Frieden IJ. Neurocutaneous melanosis: definition and review of the literature. J Am Acad Dermatol. 1991 May;24(5 Pt 1):747-55.

10. Kopf AW, Bart RS, Hennessey P. Congenital nevocytic nevi and malignant melanomas. J Am Acad Dermatol. 1979;1:123-30.

11. Viana AC, Gontijo B, Bittencourt FV. Giant congenital melanocytic nevus. An Bras Dermatol. 2013;88:863-78.

12. Slutsky JB, Barr JM, Femia AN, Marghoob AA. Large congenital melanocytic nevi: associated risks and management considerations. Semin Cutan Med Surg. 2010;29:79-84.

13. Kinsler VA, Birley J, Atherton DJ. Great Ormond Street Hospital for Children Registry for congenital melanocytic naevi: prospective study 1988-2007. Part 1-epidemiology, phenotype and outcomes. Br J Dermatol. 2009;160:143-50.

14. Arneja JS, Gosain AK. Giant congenital melanocytic nevi. Plast Reconstr Surg. 2009:12:1e-13e

15. Strauss RM, Newton Bishop JA. Spontaneous involution of congenital melanocytic nevi of the scalp. J Am Acad Dermatol. 2008:58:508-11.
16. Krengel S, Hauschild A, Schäfer T. Melanoma risk in congenital melanocytic naevi: a systematic review. Br J Dermatol. 2006;155:1-8

17. Hale EK, Stein J, Ben-Porat L, Panageas KS, Eichenbaum MS, Marghoob AA et al. Association of melanoma and neurocutaneous melanocytosis with large congenital melanocytic naevi--results from the NYU-LCMN registry. Br J Dermatol. 2005;152:512-7.

18. Tannous ZS, Mihm MC Jr, Sober AJ, Duncan LM. Congenital melanocytic nevi: clinical and histopathologic features, risk of melanoma, and clinical management. J Am Acad Dermatol. 2005;52:197-203.

19. Bittencourt FV, Marghoob AA, Kopf AW, Koenig KL, Bart RS. Large congenital melanocytic nevi and the risk for development of malignant melanoma and neurocutaneous melanocytosis. Pediatrics. 2000;106:736-41

20. Kovalyshyn I, Braun R, Marghoob A. Congenital melanocytic naevi. Australas J Dermatol. 2009;50:231-40

21. Marghoob AA, Bittencourt FV, Kopf AW, Bart RS. Large congenital melanocytic nevi. Curr Probl Dermatol 2000;12:146-52.

22. Koot HM, de Waard-van der Spek F, Peer CD, Mulder PG, Oranje AP. Psychosocial sequelae in 29 children with giant congenital melanocytic naevi. Clin Exp Dermatol. 2000;25:589-93.

23. Marghoob AA, Borrego JP, Halpern AC. Congenital melanocytic nevi: treatment modalities and management options. Semin Cutan Med Surg. 2007;26:231-40

24. Egan CL, Oliveria SA, Elenitsas R, Hanson J, Halpern AC. Cutaneous melanoma risk and phenotypic changes in large congenital nevi: a follow-up study of 46 patients. J Am Acad Dermatol. 1998;39:923-32.

25. DeDavid M, Orlow SJ, Provost N, Marghoob AA, Rao BK, Wasti Q, et al Neurocutaneous melanosis: clinical features of large congenital melanocytic nevi in patients with manifest central nervous system melanosis. J Am Acad Dermatol. 1996;35:529-38.

26. Marghoob AA, Schoenbach SP, Kopf AW, Orlow SJ, Nossa R, Bart RS. Large congenital melanocytic nevi and the risk for the development of malignant melanoma: a prospective study. Arch Dermatol. 1996;132:170-5.

27. Kaplan EL, Meier P. Non-parametric estimation from incomplete observations. Am Stat Assoc. 1958;53:457-81.

28. inca.gov.br [Internet]. Instituto Nacional de Câncer. Coordenação de Prevenção e Vigilância. Câncer no Brasil: dados dos registros de base populacional. Rio de Janeiro: INCA; 2010. 487p. [acesso 10 Jul 2011]. Disponível em: http://www. inca.gov.br/cancernobrasil/2010/ 
29. Kinsler V, Bulstrode $\mathrm{N}$. The role of surgery in the management of congenital melanocytic naevi in children: a perspective from GreatOrmondStreetHospital. J Plast Reconstr Aesthet Surg. 2009;62:595-601.

30. Ka VS, Dusza SW, Halpern AC, Marghoob AA. The association between large congenital melanocytic naevi and cutaneous melanoma: preliminary findings from an Internet-based registry of 379 patients. Melanoma Res. 2005;15:61-7.

31. Zaal LH, Mooi WJ, Sillevis Smitt JH, van der Horst CM. Classification of congenital melanocytic naevi and malignant transformation: a review of the literature. $\mathrm{Br} \mathrm{J}$ Plast Surg. 2004;57:707-19

32. Rhodes AR, Wood WC, Sober AJ, Mihm MC Jr. Nonepidermal origin of malignant melanoma associated with a giant congenital nevocellular nevus. Plast Reconstr Surg. 1981;67:782-90.

33. Lorentzen $M$, Pers $M$, Bretteville-Jensen $G$. The incidence of malignant transformation in giant pigmented nevi. Scand J Plast Reconstr Surg. 1977;11:163-7.

34. Zaal LH, Mooi WJ, Klip H, van der Horst CM. Risk of malignant transformation of congenital melanocytic nevi: a retrospective nationwide study from The Netherlands. Plast Reconstr Surg. 2005;116:1902-9.

35. Kinsler VA, Birley J, Atherton DJ. GreatOrmondStreetHospital for Children Registry for Congenital Melanocytic Naevi: prospective study 1988-2007. Part 2--Evaluation of treatments. Br J Dermatol. 2009;160:387-92.

36. Marghoob AA, Agero AL, Benvenuto-Andrade C, Dusza SW. Large congenital melanocytic nevi, risk of cutaneous melanoma, and prophylactic surgery. $J$ Am Acad Dermatol. 2006;54:868-70.

37. Kanzler MH. Management of large congenital melanocytic nevi: art versus science. J Am Acad Dermatol. 2006;54:874-6

38. Bett B. Large or multiple congenital melanocytic nevi: occurrence of cutaneous melanoma in 1008 persons. J Am Acad Dermatol. 2005;52:793-7.

39. Arneja JS, Gosain AK. Giant congenital melanocytic nevi of the trunk and an algorithm for treatment. J Craniofac Surg. 2005;16:886-93.

40. DeDavid M, Orlow SJ, Provost N, Marghoob AA, Rao BK, Huang CL, et al. A study of large congenital melanocytic nevi and associated malignant melanomas: review of cases in the New York University Registry and the world literature. J Am Acad Dermatol. 1997;36:409-16.

41. Ruiz-Maldonado R, Tamayo L, Laterza AM, Durán C. Giant pigmented nevi: clinical, histopathologic, and therapeutic considerations. J Pediatr. 1992;120:906-11.

42. Kinsler VA, Chong WK, Aylett SE, Atherton DJ. Complications of congenital melanocytic naevi in children: analysis of 16 years' experience and clinical practice. Br J Dermatol. 2008;159:907-14

43. Marghoob AA, Dusza S, Oliveria S, Halpern AC. Number of satellite nevi as a correlate for neurocutaneous melanocytosis in patients with large congenital melanocytic nevi. Arch Dermatol. 2004;140:171-5.

44. Sandsmark M, Eskeland G, Ogaard AR, Abyholm F, Clausen OP. Treatment of large congenital naevi: a review and report of six cases. Scand J Plast Reconstr Surg Hand Surg. 1993;27:223-32.

45. Arneja JS, Gosain AK. Giant congenital melanocytic nevi. Plast Reconstr Surg. 2007;120:26e-40e.

46. Marghoob AA, Schoenbach SP, Kopf AW, Orlow SJ, Nossa R, Bart RS. Large congenital melanocytic nevi and the risk for the development of malignant melanoma. A prospective study. Arch Dermatol. 1996;132:170-5.

47. Greggi S, Losito S, Pisano C, Desicato S, Scaffa C. Malignant melanoma of the vagina: report of two cases and review of the literature. Int Surg. 2010;95:120-5.

48. Das P, Kumar N, Ahuja A, Jain A, Ray R, Sarkar C, et al. Primary malignant melanoma at unusual sites: an institutional experience with review of literature. Melanoma Res. 2010;20:233-9.

49. De Almirón AC, Almazán-Fernández FM, Serrano-Ortega S. Acerca de la edad de malignización de los nevus melanocíticos congénitos. Actas Dermosifilogr. 2009;100:84-85.

50. Yun SJ, Kwon OS, Han JH, Kweon SS, Lee MW, Lee DY, et al. Clinical characteristics and risk of melanoma development from giant congenital melanocytic naevi in Korea: a nationwide retrospective study. Br J Dermatol. 2012;166:115-23.

\author{
MAILING ADDRESS: \\ Flávia Vasques Bittencourt \\ Alameda Álvaro Celso, 55 \\ Santa Efigênia \\ 30150-260 - Belo Horizonte - MG \\ Brazil \\ E-mail:flaviavbi@gmail.com
}

